\title{
JOGOS DISCURSIVOS: DOMINAÇÃO E RESISTÊNCIA NA AMÉRICA LATINA ${ }^{1}$.
}

\author{
Angela Patricia Felipe Gama \\ Graduada em Letras pela UNESP. Professora da rede pública do Estado de São Paulo e \\ pesquisadora de Comunicação e Semiótica, com foco em América Latina. \\ Email: angelapfgama@yahoo.com.br
}

\section{Fábio Marques de Souza}

Formando em Letras na UNESP. Desenvolve pesquisas relacionadas a políticas lingüísticas na América Latina e formação de Professores de Espanhol-Língua Estrangeira.

Email: fabio_unesp_br@hotmail.com

\section{RESUMO}

Toda forma de dominação se dá, primeiramente, no discurso. A língua, ao mesmo tempo em que aproxima, domina, exemplo dessa 'aproximação' foi a escolha da cidade de Rosario (Argentina) como "Capital da Língua Espanhola” para sediar - em 2004 - o III Congresso Internacional da Língua Espanhola, organizado pela Academia Real Espanhola e realizado pelo Instituto Cervantes. A iniciativa gerou um contra-congresso: o I Congresso daS LínguaS: para o reconhecimento de uma Iberoamérica pluricultural e multilíngüe - que surgiu como forma de luta e resistência de movimentos sociais e políticos locais. Atitudes como essa pode ser o primeiro passo para que abandonemos o plano da utopia rumo à realidade transformadora. $\mathrm{O}$ contra-congresso do qual participamos será o foco deste artigo, onde discutimos o papel da língua como meio de transformação da realidade.

Palavras-Chave: Discurso. Multilíngüe. América Latina.

\begin{abstract}
Every form of domination takes place in the discourse firstly. At the same time language approaches people, it also dominates them. An example of such "approach" was the choice upon the city of Rosaria, in Argentina, as the "Capital of the Spanish Language" to host the 2004 III International Congress of the Spanish Language, organized by the Royal Spanish Academy and held by the Cervantes Institute. This choice generated a counter-congress: The I Congress of Languages: for the recognition of a pluricultural and multilingual Ibero-America - a way to fight and resist social and political local movements. Attitudes like this one may be the first step to leave the utopia stage and move toward a changing reality. The counter-congress, which we attended, shall be the focus of this article where we discuss the role of the language as a means to transform reality.
\end{abstract}

Key words: Discourse. Multilingual. Latin American. 
A palavra é o homem mesmo. Estamos feitos de palavras. Elas são a única realidade ou, ao menos, o único testemunho de nossa realidade. (Octávio Paz)

Para discorrer sobre o fenômeno da dominação lingüística, faz-se necessário definir e situar a língua enquanto bem da humanidade e 'contrato social' institucionalizado, pelo qual nos definimos e interpretamos a realidade que nos cerca.

Dessa forma, pode-se inferir que a língua é meio e fim de um processo de socialização, como apresenta Calvet (1975 apud NEGRO, 2004):

Uma língua é falada por pessoas, no seio de uma sociedade, ela mesma permeada por conflitos sociais, por tensões, por lutas, que é herdeira de uma história marcada por entraves. ${ }^{2}$

Em toda sociedade a produção do discurso é controlada, selecionada, organizada e distribuída por mecanismos que possibilitam a dominação social. Desta forma pode-se concluir que o discurso é veiculado pela língua, que, quando controlada, garante o domínio.

Neste trabalho, ao fazer referência ao discurso, compartilhamos da visão de Maingueneau (2000), para ele este termo designa menos um campo de investigação delimitado do que um certo modo de apreensão da linguagem: considerado como a atividade de sujeitos inscritos em contextos determinados.

Nesta mesma linha temos Barros (2002), que apresenta a Análise do Discurso como algo que "vai além da dimensão da palavra ou da frase e se preocupa com a organização global do texto ${ }^{3}$; examina as relações entre a enunciação e o discurso enunciado e os fatores sócio-históricos que o constroem”.

\section{Fonte de pesquisa e reflexão:}

Este artigo tem como ponto de partida nossa experiência enquanto cientistas da linguagem - graduandos em Letras, participantes do I Congreso de laS LenguaS (considerado como opositor do III Congreso Internacional de la Lengua Española).

\footnotetext{
${ }^{1}$ Uma versão preliminar deste texto foi apresentada na comunicação "O reconhecimento de uma América Latina plural e multilingüe: utopia ou realidade?” durante o I Simpósio Estadual: Lutas Sociais na América Latina. UEL, setembro de 2005.

${ }^{2}$ Una lengua es hablada por gentes, en el seno de una sociedad, ella misma atravesada por confictos sociales, por tensiones, por luchas, que es heredera de una historia colmada de transtornos.

${ }^{3}$ Nesta concepção, Texto deve ser entendido como algo que "se organiza e produz sentidos, como um objeto de significação" (BARROS, 2002).
} 
Nesta oportunidade, pudemos, durante a semana que passamos na cidade de Rosario ${ }^{4}$, vivenciar - com olhos estrangeiros - as discussões geradas em torno da unidade da língua espanhola.

Desta viagem trouxemos jornais e documentos difundidos pela imprensa local, além de livros lançados durante os eventos. É a análise dessas fontes - com olhares da Análise do Discurso (escola francesa) - que nos permite traçar as considerações apresentadas.

\section{Contribuições Teóricas:}

Lançamos mão da visão de língua enquanto identidade reprodutora de ideologia e da indissociabilidade entre língua e cultura propostas por Sapir e Whorf (apud SOARES, 1989). para iniciar este trabalho. Para discorrer sobre a veiculação ideológica

através do discurso, tivemos como base as teorias de Foucault (1996). Pensando então o discurso como mecanismo de transformação da realidade e de reação à dominação, compartilhamos as idéias de Bakhtin (1978) e Fairclough (2001).

Sapir e Whorf vêem a língua como uma possibilidade de organização de elementos do mundo real que permite a interação entre os seres humanos. Dentro desta visão, uma vez que a língua organiza, ela confere sentidos e dá formas ao que cada um chama de real, sendo os elementos comuns aos falantes de determinada comunidade lingüística que constituem sua realidade.

Neste mesmo sentido temos Bakhtin (1978), para o qual o princípio da linguagem parte do fato de que sua realidade fundamental é o fenômeno social da interação verbal. A linguagem e a atividade humana estão sempre relacionadas, de tal forma que os sujeitos - socialmente organizados e marcados por intensa heterogeneidade - estabelecem relações sociais múltiplas e não coincidentes com as relações estabelecidas por outros, ainda que pertençam ao seu mesmo grupo social:

Tudo se reduz ao diálogo, à contraposição dialógica enquanto centro. Tudo é meio, o diálogo é o fim. Uma só voz nada termina, nada resolve. Duas vozes são o mínimo de vida.

O termo 'discurso' refere-se à linguagem como forma de prática social. Segundo Fairclough (2001), o discurso é uma forma que permite às pessoas agirem sobre o mundo e sobre os outros, de tal modo que a prática, tanto de representação quanto de significação do mundo, o molda e o restringe.

${ }^{4}$ Cidade da República Argentina que sediou - simultaneamente - os dois eventos. 
Ao construir o mundo, o discurso também constrói identidades sociais, estabelece relações que contribuem para a formação de representações sociais. A prática discursiva, então, além de reproduzir a sociedade, também a transforma.

Para Foucault (1996, p.10), a verdade é o instrumento que possibilita controlar e dominar essas relações sociais. É no discurso que se constrói a verdade, portanto, possuir o discurso dominante é poder institucionalizar a verdade e favorecer-se dela. Nesse ponto, gera-se um embate político que tem como objetivo controla-lo:

O discurso não é simplesmente aquilo que traduz as lutas ou sistemas de dominação, mas aquilo por que, pelo que se luta, o poder do qual nos queremos apoderar.

\section{Do Congresso 'de la Lengua' ao 'de laS LenguaS':}

Quando uma sociedade se corrompe, a primeira coisa que se gangrena é a linguagem.Octávio Paz

Iniciaremos esta seção apresentando o Congresso Internacional da Língua Espanhola desde seu surgimento até sua última edição. Em seguida, disponibilizaremos informações sobre o contra-congresso e, à luz das teorias especializadas, traçaremos um paralelo entre a ideologia veiculada por cada um deles.

Organizado pela Academia Real Espanhola e pelo Instituto Cervantes, o Congresso Internacional da Língua Espanhola iniciou-se em 1992 com o "Congreso de la Lengua Española" e evoluiu até alcançar sua III edição em 2004 com o tema "Identidade lingüística e globalização", realizado em Rosário (República Argentina) nos dias 17 a 20 de novembro. Apresentamos, no Quadro 1, sua evolução diacrônica:

Com intuito de resgatar e preservar a memória dos conflitos de 'libertação’ da América Latina cabe, neste momento, traçar considerações sobre a

\begin{tabular}{|c|c|c|}
\hline ANO & EVENTO & LOCALIDADE \\
\hline 1992 & Congreso de la lengus Exponola & Sevilla (Espana) \\
\hline 1997 & ICongreso Internadional de la Lengua Espanola & Zacanecas (Mexiko) \\
\hline 2001 & $\begin{array}{l}\text { II Congreso Lnternacional de la Lengua Espafola } \\
\text { sEl español en la Sociedad de la Información. }\end{array}$ & Vhlodolid (Eq̧uña) \\
\hline 2004 & $\begin{array}{l}\text { III Congreso Innernacional de la Lengua Espanola } \\
\text {-Identidad Lingaistica e dobaligación. }\end{array}$ & $\begin{array}{l}\text { Roeario } \\
\text { (Republica Ansentina) }\end{array}$ \\
\hline
\end{tabular}


origem da Academia Real Espanhola e do Instituto Cervantes. Este último é um organismo que foi criado pela Espanha, em 1991, cuja missão principal é difundir sua língua pelo mundo e, aquela com antecedentes históricos quase não dominadores:

Fundada em 1714 sob o reinado de Felipe V - que unificou o Reino da Espanha e tornou o castelhano em língua obrigatória para todos os súditos da coroa, o que implicou nos territórios conquistados na própria Península Ibérica, a mudança de nome dos povoados (tradução para o castelhano), a proibição de outras línguas e a queima de bibliotecas. ${ }^{5}$ (CONGRESO DE LAS LENGUAS, 2004).

Vemos então a força que uma língua exerce - pelo poderio bélico - em função de outras, e assim deforma maneiras peculiares de ver o mundo. A respeito das relações entre língua e sociedade, Sapir diz que a língua determina as percepções e o pensamento:

Os seres humanos estão quase inteiramente à mercê da língua particular que é o meio de expressão de sua comunidade: o 'mundo real' é, em grande parte ou na sua totalidade, construído pelos hábitos de linguagem do grupo. Vemos, ouvimos e vivemos nossas experiências tal como o fazemos porque os hábitos de linguagem de nossa comunidade predispõem-nos a certas opções de interpretação (ULLMANN apud SOARES, 1989).

Assim sendo, Whorf, discípulo de Sapir, afirma também que a língua determina a visão de mundo dos que a falam:

O sistema lingüístico básico de cada língua não é meramente um instrumento de reprodução de idéias, mas é, sobretudo, um formador de idéias, o programa e guia para a atividade mental do indivíduo [...]. Dissecamos a natureza segundo as diretrizes fixadas por nossas línguas nativas. As categorias e os tipos que isolamos do mundo dos fenômenos não os encontramos ali porque saltam à vista de qualquer observador [...]. Cortamos a natureza em pedaços, organizamo-la em conceitos e lhe atribuímos significação tal como fazemos primordialmente porque somos parte de um acordo válido para toda nossa comunidade lingüística e que está codificado na estrutura de nossa língua (WHORF, 1971).

Como forma de resistência, em favor da preservação da identidade de um povo, surgiu o "Congreso de laS lenguaS", importante movimento cultural e reivindicatório dos diferentes valores que as línguas indígenas - as que ainda sobrevivem e aquelas a serem recuperadas - nos oferecem, como também as variadas formas do castelhano configuradas no continente (Dr. Adolfo Pérez Esquivel, prêmio Nobel da paz, presidente honorário do evento).

\footnotetext{
${ }^{5}$ Entenda-se, neste trabalho, a língua Castelhana (do Reino de Castela) como sendo sinônimo -
} ainda que não exista, para a lingüística, sinônimo perfeito - de Língua Espanhola. 
Como forma de resistência, em favor da preservação da identidade de um povo, surgiu o "Congreso de laS lenguaS" que, conforme apresentou o presidente honorário do evento, Dr. Adolfo Pérez Esquivel, tratou-se de um importante movimento cultural e reivindicatório dos diferentes valores que as línguas indígenas - as que ainda sobrevivem e aquelas a serem recuperadas - nos oferecem, como também as variadas formas do castelhano configuradas no continente. Neste mesmo sentido, compartilhamos da idéia apresentada pelo artigo "Por el reconocimiento de una América pluricultural y multilingüe" 6 que apresenta a Iberoamérica como espaço crucial da diferença, onde a alteridade é a razão de ser da identidade e da diversidade, além de ser a fonte criativa do desenvolvimento cultural. Dessa forma, toda

\section{Charge 1}

- Senhor... o senhor que saber muito... tirar a lingua... não ser falta de respeito?

Charge publicada no jornal "La Capital" em 16/11/2004 - quando da chegada do Reis Espanhóis para participação no III Congresso Internacional da Língua Espanhola.

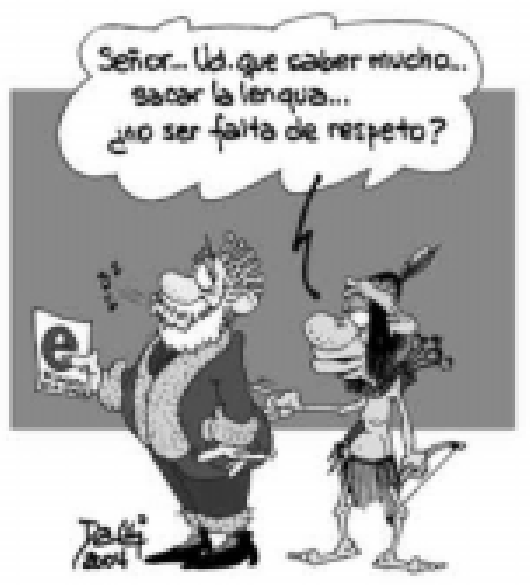

Charge 02

- Não entendo... o senhor esteve em um congresso com os Reis e noutro com indígenas..Qual é a explicação racional?. - E eu é que sei?... na verdade, o que eu gosto mesmo são dos congressos!

Jornal de 21/11/2004 - Ironizando o fato da participação do escritor português José Saramago no dois eventos.

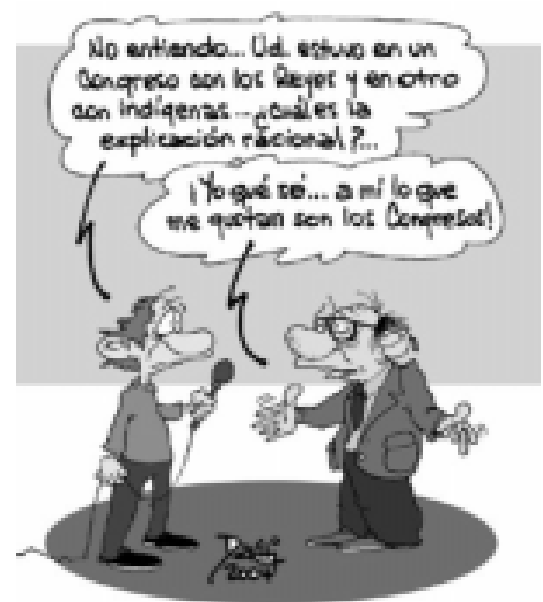

\footnotetext{
${ }^{6}$ Fundada en 1714 bajo el reinado de Felipe V, quien unificó el Reino de España y convirtió el castellano en lengua obligatoria para todos los súbditos de la corona, lo cual implicó, en lo territorios conquistados en la propia Península Ibérica, el cambio de nombre de los pobladores (tradución al castellano), la prohibición de otras lenguas y quema de bibliotecas.
} 
cultura é uma intercultura que utiliza a língua como um veículo vivo de comunicação. E será na interação e na continuidade que se estabelecerá um diálogo frutífero entre os povos. $\mathrm{O}$ intento de homogeneização tem como efeito à destruição de características únicas de cada povo, utilizando, muitas vezes, a língua como ferramenta de poder.

O Congresso aconteceu nos dias 15 à 20 de novembro. Os eixos de discusão foram: lenguas e identidade (individual, social e étnica), línguas e educação, línguas e direitos humanos, línguas e gênero, línguas - historia e sociedade, línguas e meios de comunicação, línguas e expresões artísticas, línguas e políticas públicas.

O evento foi organizado sob a liderança do Prof. Dr. Rodolfo R. Hachén, docente e investigador da Universidad Nacional de Rosario (UNR), e contou com o apóio das entidades organizadoras:

- SERPAJ Servicio de Paz y Justicia (Buenos Aires);

- ÍCARO "Instituto de Artes Contemporáneas de Rosario";

- Cátedra de Etnolingüística (Escuela de Antropología, Facultad de Humanidades y Artes, Universidad Nacional de Rosario);

- Biblioteca "Juan Manuel Rodríguez" del Centro Cultural de La Toma (Rosario);

- Historia Obrera Zona Norte (Rosario) ;

- Núcleo de Estudios del Trabajo y la Conflictividad Social (NET);

- MNER Movimiento Nacional de Empresas Recuperadas (Buenos Aires);

- IMPA La fábrica Ciudad Cultural (Buenos Aires);

- Mesa de Trabajo Pueblos Originarios de Rosario;

- Editorial Juglaría (Venado Tuerto - Rosario); Movimiento de Documentalistas (Argentina);

Dizem que tem sete línguas a boca do dragão. Eu não sei. Mas me consta que muitas mais línguas têm a boca do mundo, e o fogo de suas línguas nos abriga. Será sempre pouco quanto se faça para defendê-las do desprezo e do extermínio. (Eduardo Galeano, para o I Congresso daS línguaS).

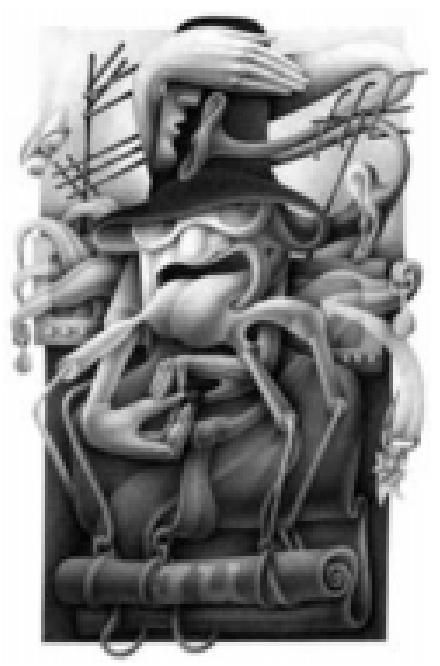

Figura 1: Logotipo oficial do evento. 


\section{Considerações finais}

Para garantir o princípio fundamental da linguagem baseado no fenômeno social da interação verbal, como propõe o teórico russo Bakhtin (1978), surge à necessidade elementar de ver ao outro: de dar voz aos seus sentimentos e, dentro deste raciocínio o evento tem seu destaque: propiciou discussões em torno do objeto 'língua' sempre tomando como base as cores e caracteres locais - contanto com a sabedoria dos povos originários?

Cruz, Souza e Lima (2004, p.12) ao escreverem sobre o contra-congresso alegam que "foi um espaço que privilegiou a importância das variantes lingüísticas”, eles apresentam ainda que tiveram a oportunidade de participar de um evento onde "se levou em conta que cada variante representa uma visão particular de mundo, preservando a identidade dos que a falam”.

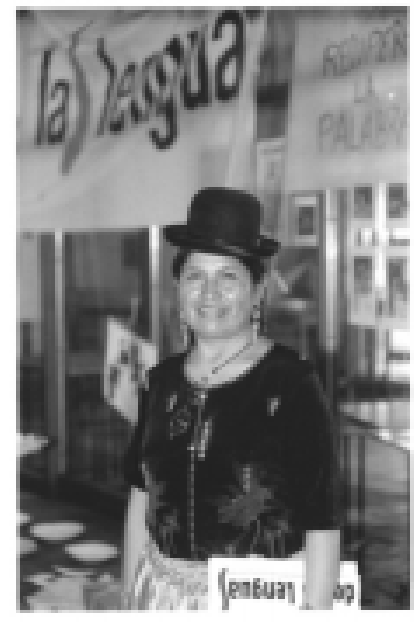

Foto 1: Representantes dos povos originários durante o evento.

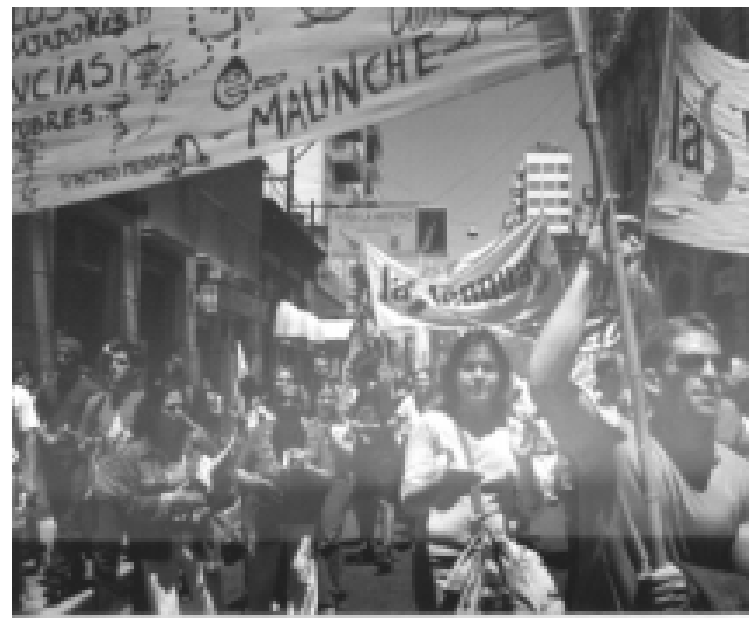

Foto 2: Participantes em passeata de manifestação (17/11/2004)

O "I Congreso de laS lenguaS" foi um passo das minorias, ainda que isoladas, em busca da tomada do discurso (FOUCAULT, 1996, p.10) para assim se construir a verdade desde o ponto de vista dos dominados institucionalizando-a - com o intuito de que o reconhecimento de uma América Latina plural e multilingüe venha a ser realidade.

\footnotetext{
${ }^{7}$ As fotos 1 e 2 foram gentilmente cedidas pelo amigo rosarino Esteban Dickstein, a quem agradecemos pela colaboração.
} 


\section{REFERÊNCIAS}

ALDERETES, Jorge R.; ALDERETES, Lelia Albarracín. La lengua que habitamos. In: CONGRESO DE LAS LENGUAS: por el reconocimiento de una Iberoamérica pluricultural e multilingüe,1., 2004, Rosario (Argentina). Actas... Rosário, 2004. BAKHTIN, Mikhail. Marxismo e filosofia da linguagem. São Paulo: Hucitec, 1978. BARROS, D. L. P. Estudos do Discurso. In: FIORIN, J. L. (Org.). Introdução à Lingüística: II. Princípios de Análise. São Paulo: Contexto, 2002.

CONGRESO DE LAS LENGUAS: por el reconocimiento de una Iberoamérica pluricultural e multilingüe,1., 2004, Rosario (Argentina). Actas... Rosário, 2004.

CRUZ, Maria de Lourdes Otero Brabo; SOUZA, Fábio Marques de; LIMA, Luis Fernando Martins de. Aquisição lingüístico-cultural de espanhol-lingua estrangeira (E-LE) mediada pelo cinema: um estudo de representações. 2004. no prelo.

EL ESPAÑOL da Batalla: III Congreso de la lengua. Revista de Cultura, Buenos Aires, n. 59, Edición especial, 2004.

FAIRCLOUGH, N. Discurso e mudança social. Brasília: UNB, 2001.

FENOY, Blanca Liliana. El decir del otro: políticas de la escucha. In: CONGRESO DE LAS LENGUAS: por el reconocimiento de una Iberoamérica pluricultural e multilingüe,1., 2004, Rosario (Argentina). Actas... Rosário, 2004.

FOUCAULT, M. A Ordem do Discurso. São Paulo: Loyola, 1996.

HACHÉN, Rodolfo Raúl. Esa maldita ese... Acerca de la pluralidad y otras yerbas. In: CONGRESO DE LAS LENGUAS: por el reconocimiento de una Iberoamérica pluricultural e multilingüe,1., 2004, Rosario (Argentina). Actas... Rosário, 2004.

MAINGUENEAU, Dominique. Termos-chave da Análise do Discurso. Belo Horizonte: UFMG, 2000.

NEGRO, María Pilar García. Antigüedad y modernidad de la lengua gallega. las propuestas de la legalidad/vs/ las propuestas de la necesidad. In: CONGRESO DE LAS LENGUAS: por el reconocimiento de una Iberoamérica pluricultural e multilingüe,1., 2004, Rosario (Argentina). Actas... Rosário, 2004.

REAL ACADEMIA ESPAÑOLA. INSTITUTO CERVANTES. III Congreso Internacional de la Lengua Española "Identidad lingüistica y globalización": Programa Acadêmico. Rosario, 2004.

SOARES, Magda. Linguagem e escola: uma perspectiva social. São Paulo: Ática, 1989. TORREALDAI, J.M. El libro negro del Euskera. Navarra: Ttarttalo, 2003.

WHORF, Benjamin Lee. Lenguaje, pensamiento y realidad. Barcelona, Barral Editores, 1971. 
